Faculdade de Ciências Econômicas UFRGS

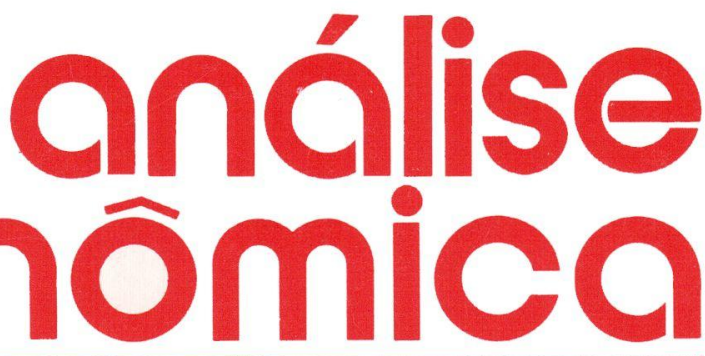

- COMÉRCIO INTERNACIONAL: UMA AGENDA DE PESQUISAS Carlos Alberto Primo Braga

- INFLACÃO E REFORMA MONETÁRIA: KEYNES E MISES Francisco Anuatti

- A ECONOMIA COMO CIÉNCIA Eleutério F.S. Prado

- REAVAlIAÇ̃̃o das PRIVATIZAÇÕES EM PAÍSES EUROPEUS

Márcio Wohlers de Almeida

- INTEGRAÇÃo BRASIL-ARGENTINA E A PRODUÇÃO DE GRÃOS José Eduardo Gutiérrez Perez Walter José Stülp

- SUBSTITUIÇÃO DE COLONOS POR TRABALHADORES ASSALARIADOS

Carlos José Caetano Bacha

- EQUILÍBRIO DISTRIBUTIVO EM MODELOS KALDORIANOS AMPLIADOS Joanílio Rodolpho Teixeira Jorge Thompson Araújo

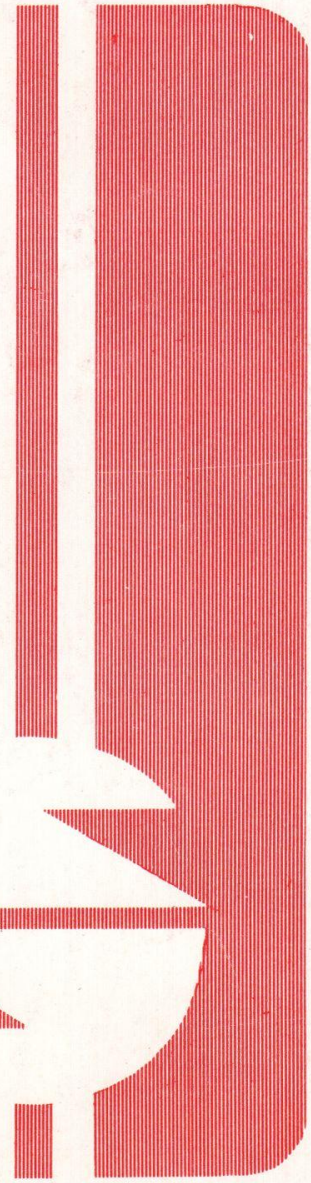


UNIVERSIDADE FEDERAL DO RIO GRANDE DO SUL.

Reitor: Prof. Tuiskon Dick

FACULDADE DE CIËNCIAS ECONÔMICAS

Diretor. Prof. Walter Meucci Nique

CENTRO DE ESTUDOS E PESQUISAS ECONÔMICAS

Diretor. Prof. Reinaldo Ignacio Adams

DEPARTAMENTO DE CIÊNCIAS ECONÔMICAS

Chefe: Prof. Pedro Cezar Dutra Fonseca

CURSO DE PÓS-GRADUAÇĀO EM ECONOMIA

Coordenador. Prof. Roberto Camps Moraes

CURSO DE PÓS-GRADUAÇĀO EM ECONOMIA RURAL

Coordenador. Prot. Aray Miguel Feldens

CONSELHO EDITORIAL:

Achyles Barcelos da Costa, Aray Miguel Feldens, Atos Freitas Grawunder, Carlos Augusto Crusius, Emani Hickmann, João Rogério Sanson, Juvir Luiz Mattuella, Maria Imilda da Costa e Silva; Nali de Jesus de Souza, Nuno Renan Lopes de Figueiredo Pinto, Ot́lia Beatriz Kroeff Carrion, Otto Guilherme Konzen, Paulo Alexandre Spohr, Pedro Cezar Dutra Fonseca, Reinaldo Ignacio Adams, Roberto Camps Moraes, Valter José Stülp, Yeda Rorato Crusius, Edgar Augusto Lanzer (UFSC) e Humberto Vendelino Richeter (UnB)

COMISSĀO EDITORIAL: Atos Freitas Grawunder, Pedro Cezar Dutra Fonseca, Reinaldo Ignacio Adams e Roberto Camps Moraes.

EDITOR: Nali de Jesus de Souza

SECRETARIA: Francisco Carlos Becco dos Santos, Maria Ivone de Mello (normalização), Vanete Ricacheski (revisão de textos), Wagner Nunes e Zélide Bregalda.

FUNDADOR: Prof. Antônio Carlos Santos Rosa

A Revista ANÁLISE ECONÔMICA publica dois números anuais nos meses de março e novembro. O preço da assinatura, para 1990, é de 7,0 BTNs (o número avulso custa 4 BTNs), a ser pago através de cheque nominal em nome da "Faculdade de Ciências Econômicas/ UFRGS". Aceita-se permuta com revistas congêneres. Aceitam-se, também, livros para elaboração de resenhas ou recensōes.

Toda correspondência, material para publicação, assinaturas e permutas devem ser dirigidos ao seguinte destinatário:

PROF. NALI DE JESUS DE SOUZA

Revista Análise Econômica

Av. João Pessoa, 52 - sala 28

90.040 - PORTO ALEGRE (RS) - BRASIL

Telefone: 25-5844 ramal 34 


\title{
A INTEGRAÇÃO BRASIL - ARGENTINA E A PRODUÇÃO DE GRÃOS
}

\author{
José Eduardo Gutiérrez Perez ${ }^{*}$ \\ Valter José Stülp* *
}

\section{INTRODUÇÃO}

As negociações entre o Brasil e a Argentina, tendentes a desenvolver um processo de integração sub-regional, têm sido qualificadas como um fato político da maior importância, por abrir amplas possibilidades de cooperação e articulação entre os dois países, além do que podem se constituir num núcleo de concerto econômico entre os países da América Latina.

Embora normalmente se pense que a integração econômica seja um instrumento favorável ao desenvolvimento, pois ambos os paises poderiam ganhar com a poupança de divisas, com as economias de escala e com a tendência de especialização, aumentando a eficiência, a produtividade e a competitividade, esta mesma integração não deixa de suscitar preocupações.

Dentre as preocupaçōes, do lado brasileiro e, principalmente, na Região Sul do pals, estão aquelas relacionadas com as desigualdades nos processos produtivos do setor agropecuário, onde a Argentina compete na produção de frutas de clima temperado e de seus derivados (vinhos, compotas, etc.), na produção de came e de grãos. Considerando estas preocupaçōes, o estudo tem por objetivo avaliar os efeitos da integração entre os dois paises sobre a produção de trigo, milho, soja e arroz, identificando, ainda, algumas medidas de política econômica tendentes a atenuar os impactos negativos sobre esta produção.

\footnotetext{
* Mestre em Economia Rural pelo IEPE/UFRGS.

** PhD em Economia Bural e professor da UFRGS. Os autores agradecem à Eliane S. Visnievski e à Lisiane R. Correa pela colaboração nos serviços datilográficos.
} 
Especificamente, os objetivos são:

a) fazer uma análise comparativa da estrutura e dimensão dos custos de produção destes bens nos dois países;

b) identificar os principais impactos que resultariam de uma liberação do comércio com a Argentina no fluxo dos bens considerados; de comércio.

c) avaliar o efeito de medidas de política económica sobre o fluxo

\section{OS PRODUTOS E A ÁREA DE ESTUDO}

Os produtos considerados neste estudo são de grande importância tanto no Brasil como na Argentina, razão pela qual uma liberaçāo de comércio entre os dois países poderia gerar efeitos de grandes implicaçōes econômicas e sociais.

No qüinqüênio 1982-86, os quatro produtos utilizaram, no Brasil, $77 \%$ da área ocupada e geraram $61 \%$ do volume produzido pelas 15 culturas temporárias alimentlcias mais importantes, reportadas pela Fundação Instituto Brasileiro de Geografia e Estatística (FIBGE-1985 e 1986).

A soja e o trigo ainda se destacam pela sua participação no comércio exterior. No periodo 1982-84, as exportações brasileiras de soja e derivados representaram $23 \%$ das exportaçőes mundiais do produto (ORTMANN, G.; STULP, V.; RASK, N. 1986). O trigo é o principal item nas importaçōes brasileiras de produtos agrícolas, sendo que, no periodo $1979-85$, o pais foi o quarto maior importador deste cereal, depois da URSS, China e Japão.

$\mathrm{Na}$ Argentina, as lavouras que têm ocupado as maiores âreas, nos anos recentes, são o trigo, o milho e a soja, juntamente com o girassol (BOLSA DE CEREALES DE BUENOS AIRES).

A agropecuária participou em $75 \%$ no total das exportaçōes argentinas no qüinqüênio 1980-84. Neste mesmo penlodo, os cereais e oleaginosas responderam por $50 \%$ do valor das exportações totais (FUENTES, H.A., 1987).

No perfodo de $1982-84$, a Argentina foi o $2^{\circ}$ maior exportador de milho, o $3^{\circ}$ maior exportador de soja e $05^{\circ}$ colocado na exportação de trigo (ORTMANN, G.; STULP, V.; RASK, N. 1986).

As áreas abrangidas pelo estudo são as unidades político-administrativas dos países que, historicamente, foram o cenário da concentração e do desenvolvimento dos complexos de produção e transformação dos produtos considerados. 
Os estados do Rio Grande do Sul e Paraná e os mais meridionais do Centro-Oeste e do Sudeste, ou seja, Mato Grosso do Sul e São Paulo concentram considerável parcela da produção primária e transformação industrial dos quatro produtos.

No qüinqüênio 1982/86, aproximadamente $98 \%$ da produção brasileira de trigo e $78 \%$ da de soja teve estes estados como origem. Em relação ao milho e arroz, a participação destes estados é menor, pela ampla adaptação destes a diversas condições ecológicas, à alta proporçāo de consumo final sem requerimentos sofisticados de processamento e, no caso do milho, pela sua utilização como insumo nas atividades pecuárias. Estes aspectos associados ao fato destes dois produtos serem importantes componentes do consumo na economia camponesa conduzem a uma grande dispersão de sua produção.

Ainda assim, por razões ligadas à eficiência produtitiva, especialização da produção para o mercado, qualidade do produto, etc., os quatros estados continuam sendo de grande importância: Em relação ao milho, $46 \%$ da área foi semeada e $55 \%$ do volume foi produzido nestes estados, no qüinqüênio 1982-86, evidenciando melhores niveis de produtividade. No mesmo período, estes estados participaram com $27,7 \%$ da área semeada e $43 \%$ da produção brasileira de arroz, igualmente indicando a superioridade na produtividade em relação aos demais estados do Brasil (FIBGE - 1985 e 1986).

Pelas razōes acima colocadas, a área de estudo inclui os estados do Rio Grande do Sul, Paraná, São Paulo e Mato Grosso do Sul, pelo lado brasileiro.

As áreas abrangidas pelo estudo na Argentina, correspondem à regiāo do pampa, integrada pelas províncias de Buenos Aires, Santa Fé, Cordoba, Entre Rios e La Pampa.

A região pampeana, segundo MARTIN, J. (1981), sem fronteira agrícola disponível, apresenta diversificação agropecuária e uma linha de especialização baseada em culturas, principalmente de cereais. Estas caracterizam-se por serem anuais, e ter técnicas similares de produção, o que permite ampla substituição, rotação, acumulação de culturas sucessivas e complementação agrícola com a pecuária. Isto, aliado às excepcionais condições ecológicas da região, conferem a estas culturas vantagens comparativas na produção agrícola, possibilitando-lhes um amplo mercado mundial.

A região pampeana produziu, no qüinqüênio 1982-86, em relação ao total da Argentina, $98,7 \%$ do trigo, $93,9 \%$ da soja, $89,1 \%$ do milho e $49,8 \%$ do arroz (BOLSA DE CEREALES DE BUENOS AIRES). 


\section{VANTAGENS DE CUSTOS E COMPETITIVIDADE}

No centro das discussões sobre a integração, ocupam lugares importantes os conceitos de vantagens, absolutas e comparativas e o de competitividade.

Segundo Adam Smith, os fluxos do comércio intemacional estariam determinados pelas diferenças absolutas entre os custos de produção (vantagens absolutas). As vantagens absolutas de custos, de um país sobre outro, na produção de determinada mercadoria, estão determinadas pelo menor custo em que ele incorre, em relação ao custo do país de referência.

Segundo o conceito das vantagens comparativas, de David Ricardo, enquanto existirem diferenças internacionais nos custos relativos de dois bens, o comércio entre nações seria mutuamente benéfico.

John Stuart Mill mostra que a amplitude das trocas internacionais dependeria, também, da demanda em determinado paiss pelo bem produzido pelo seu parceiro comercial, e não apenas das diferenças de custos (ROSSETTI, J.P. 1982).

Hecksher-Ohlin procuraram explicar as razöes das trocas internacionais com base nas diferentes dotações estruturais de recursos e nos diferentes preços dos recursos entre nações. Cada nação exportaria a mercadoria cuja produção exigiria mais do recurso relativamente mais abundante e mais barato, e importaria aquela cuja produção demandaria mais do fator que fosse relativamente mais escasso e caro (SALVATORE, D. 1984).

O conceito de competitividade procura englobar as várias razões determinantes dos fluxos de comércio internacional. Perkins (1986) definiu competitividade como a capacidade de ampliar a participação no mercado. Portanto, um pais se torna mais competitivo quando aumenta a sua capacidade de concorrer com os outros países para o atendimento das demandas por produtos no mercado internacional ou numa região integrada.

Muitos fatores influenciam na competitividade de um pais, como os seus custos marginais (funções de oferta) e funções de excesso de demanda de seus parceiros comerciais. As funções de oferta dependem dos custos de produção, transporte e comercialização. Estes custos são função do nível tecnológico, da dotação e preços dos fatores, distâncias no transporte, escala de produção, etc. e são influenciados por subsídios e impostos. 
Um deslocamento na curva de excesso de demanda do país importador vai alterar a posição relativa do exportador, se as elasticidades preço de oferta dos vấrios países exportadores são diferentes.

Portanto, enquanto os custos de produção são o elemento que melhor reflete as vantagens comparativas, o conceito de competitividade, além destes, incorpora também outras variáveis que vão definir o preço de venda.

PAARLBERG, P. (1985), citado por CIRIO, F. e REGUNAGA, M. (1987), comparando os conceitos de vantagens comparativas e competitividade, diz que "em princípio as vantagens comparativas refletem 0 que deveriam ser os fluxos comerciais num mercado sem restrições, enquanto a competitividade reflete diferenças nos preços de mercado".

A competitividade é influenciada pela mudança no custo de oportunidade dos fatores à medida que o pals produz mais ou menos de um determinado produto.

A separação geográfica dos mercados é um fator que, também, afeta a competitividade. Assim, é possivel que produções com niveis relativamente baixos de eficiência possam ser competitivas em determinados mercados, pelas vantagens devidas aos baixos custos de transporte. No caso de países subdesenvolvidos, isto adquire grande relevância, tanto no comércio extra-regional como intra-regional e, principalmente, ern relação aos produtos agropẹcuários.

$O$ transporte tem grande importância na formação das correntes de comércio. BASCO, C. (1988) afirma que os custos de transporte tendem a proteger as produções locais da concorrência externa da mesma forma que as barreiras artificiais, como as taxas alfandegárias, quotas e outras. Por outro lado, os custos de transporte também oferecem certa resistência à exportação dos excedentes de produção.

CIRIO, F. e REGUNAGA, M. (1987) colocam que as restrições introduzidas, desde o período do pós-guerra, pelas políticas agrícolas protecionistas na produção e no comércio internacional de grãos têm determinado um forte divórcio entre competitividade e vantagens comparativas, ao ponto de se encontrar palses que são competitivos - incrementam a sua participação no mercado - sem ter vantagens comparativas e outros que, mesmo tendo vantagens comparativas, pelos seus menores custos de produção, perdem competitividade. Estes autores concluem que a competitividade nos grãos da Argentina tem estado fundamentalmente baseada nas suas vantagens comparativas e nạo na aplicação de políticas que, artificialmente, compensam uma menor eficiência pro- 
dutiva via subsídios. Inclusive acrescentam que a Argentina, tradicionalmente, tem desprotegido o setor de produção de gräos mediante restrições cambiais e de impostos às exportações.

Quanto ao Brasil, LEITE DA SILVA, G. (1988) mostra que, no período 1953-1985, foi mantida uma permanente discriminação contra o setor agropecuário e que, no processo de substituição de importações, a agricultura brasileira tem suportado uma permanente taxação promovida pelo uso de tarifas alfandegárias, restrições quantitativas e sistemas de câmbio múltiplo. Portanto, a competitividade da agricultura brasileira também estaria baseada, primordialmente, nas vantagens de custos.

O presente trabalho analisa a produção brasileira de grãos comparativamente à argentina, sob o enfoque da competitividade. Esta inclui os custos econômicos de produção, considerando também aqueles referentes ao custo de oportunidade dos fatores que são função do nivel de produção, disponibilidade estrutural dos recursos, produtividade, etc.

O trabalho considera ainda custos de transporte, interferëncias governamentais, como quotas, subsídios, impostos, etc. Também as disponibilidades estruturais dos recursos, os diferentes preços dos recursos e as demandas pelos produtos, tanto nos mercados domésticos como internacional, são considerados.

\section{FONTES DE DADOS E MÉTODO}

Como característica geral, a pesquisa é de natureza estática, só abrangendo um subsetor da produção-comercialização agrícola, que é o de grãos. $E$, em relação a este, se simularam situaçōes de integraçăo econômica a fim de detectar os principais impactos no subsetor considerado. Focaliza-se a oferta e, portanto, se enfatizam os custos. Considera-se, porém, a dimensão espacial, identificando-se uma estrutura de localização das atividades de produção e de consumo, incorporando custos relativos à transferência geográfica dos produtos (fretes, cargas, descargas, pesagens, etc.). Da mesma forma, foram incluídas as restriçōes relativas à demanda dos produtos. Finalmente, depois de terem sido identificados alguns problemas centrais de integração, simularam-se barreiras artificiais (taxas alfandegárias e subsidios) visando avaliar 0 seu impacto. 


\subsection{Fontes de Dados}

Os dados usados neste trabalho são secundários. A informação geral referente à produção, consumo e comércio exterior tẹm por fonte, no Brasil, os Censos Agropecuários e os Anuários Estatísticos do Brasil da FIBGE, publicações da Carteira de Comércio Exterior do Banco do Brasil (CACEX) e dados obtidos junto à Companhia de Financiamento da Produção (CF́P).

$\mathrm{Na}$ Argentina, as principais fontes foram a Secretaria de Agricultura, Ganaderia e Pesca (SAGyP) do Ministério da Economia, a Bolsa de Cereais de Buenos Aires e a Junta de Granos.

Os coeficientes técnicos de utilização de fatores de produção, assim como as características das unidades típicas de produção, têm por fonte as entidades que, tradicionalmente, publicam essas informações em cada região. Assim, foram usadas informações publicadas pela $\mathrm{Fe}$ deração das Cooperativas de Trigo e Soja do Rio Grande do Sul Ltda (FECOTRIGO), pelo Instituto Rio-Grandense do Arroz (IRGA) e dados de estudos realizados pelo Centro de Estudos e Pesquisas Econômicas (IEPE) da UFRGS, para o estado do Rio Grande do Sul. A principal fonte de coeficientes técnicos, em relação ao Paraná, foi a Organização das Cooperativas do Estado do Paraná (OCEPAR); referente ao Mato Grosso do Sul, foi a Organização das Cooperativas Brasileiras (OCB); e, para São Paulo, foi o Instituto de Economia Agrícola da Secretaria de Agricultura deste Estado.

Em relação à Argentina, a informação sobre coeficientes técnicos e unidades de produção tem por fonte a SAGyP, o Instituto Nacional de Tecnologia Agropecuária (INTA) e o Instituto Interamericano de Cooperação para a Agricultura (IICA).

Para o Brasil, em geral, os preços dos fatores de produção usados são os reportados pelas instituiçōes fontes dos dados tecnológicos. Porém, quando possivel, usou-se também os preços reportados pela Fundação Getúlio Vargas. Isto ocorreu quando os fatores eram bem especificados (tipo, marca, região, etc.).

Os custos de transporte rodoviário têm por base as informações do Conselho Nacional de Estudos de Transporte e Tarifas (CONET), correspondentes ao serviço chamado de "Transporte de grandes massas". Informação complementar foi obtida junto ao Sindicato das Empresas de Transporte de Carga no Estado do Rio Grande do Sul. 
Os fretes marltimos têm por fonte básica o estudo realizado por BASCO, C. (1987).

Em relação à Argentina, as informações sobre preços têm por base as publicações "Boletines de Precios de Insumos Agropecuários" da SAGyP. Para alguns insumos, foi utilizada a informação das "Séries de Precios Agropecuários" da "Asociación Argentina de Consorcios Regionales de Experimentacion Agricola".

Informações sobre custos de transporte foram obtidas na Junta de Granos e correspondem às tarifas autorizadas pela instituição para as suas contratações do serviço. Todos os preços foram transformados ao nível de preços de junho de 1987. Para esta transformação, utilizou-se, no Brasil, o Indice dos Preços Pagos pelos Agricultores da Fundação Getúlio Vargas e, na Argentina, o indice de Precios Mayoristas Nivel Geral.

\subsection{O Método}

As metodologias utilizadas pelas diversas entidades, fontes das informações, para a estimativa dos custos de produção diferem em muitos aspectos, como período de vida útil das construções e máquinas, taxas de manutenção, de juros, etc. Portanto, para possibilitar as comparaçōes entre os custos nas diversas regiōes, utilizou-se uma metodologia única. Esta metodologia em questão abrange todas as operações efetuadas, desde o preparo do terreno até a entrega do produto primário ao sistema de comercialização. GUTIERREZ PEREZ, J.E. (1988) explica detalhadamente a metodologia utilizada.

Nos custos de produção, não se inclui os referentes à assistência técnica, tendo em vista que as entidades aplicam um percentual sobre o custo total, o que, arbitrariamente, aumentaria as diferenças regionais de custos. Também não foi considerado explicitamente o custo referente ao uso do fator terra, o qual, segundo muitos autores, estaria determinado pelo nivel das receitas obtidas de maneira residual. No entanto, na análise da competitividade entre as regiões, o custo da terra é levado em consideração, implicitamente, pelo seu custo de oportunidade.

Os custos totais por cultura foram também expressos em dólares. As taxas de câmbio usadas para a conversão de cruzados em dólares e de austrais em cruzados foram as médias das respectivas taxas de câmbio nominais de junho de 1983 a junho de 1987, atualizadas a junho 
de 1987. Os valores utilizados são 43,887 cruzados/dólar e 27,741 cruzados/austral.

Para a análise da competitividade na produção de grãos entre os dois países e as várias regiōes, consideraram-se, além dos custos de produção e comercialização, as demandas por estes produtos em cada país e região, e as possibilidades de importação e os compromissos de exportação para terceiros países. Igualmente, foram considerados os recursos disponíveis para a produção de grãos, em cada região.

O modelo de análise usado para a avaliação da competitividade é o de programação linear.

A função objetivo, a minimizar, é o somatório dos custos totais de produção, transporte, comercialização e importação dos produtos agricolas considerados. Esta função representa os custos de abastecimento da demanda doméstica e das exportaçōes de trigo, milho, soja e arroz da região integrada, formada pelo Brasil e Argentina.

As variáveis de decisão do modelo de análise correspondem à produção regional (por estados no Brasil) dos palses, aos fluxos de comércio intra-regionais e aos fluxos das importaçōes e exportações.

As restriçōes consideradas no modelo são as de recursos para a produção agrícola, as de abastecimento interrio, as de exportaçōes e importaçōes de terceiros paises. As restriçōes de abastecimento interas e de exportações são de mínimo, significando que a produção e importação dos produtos deve atender ao abastecimento interno e aos compromissos de exportação de cada pals. As restrições de importação são de máximo, indicando que é possível atender ao consumo interno, via importações de terceiros paises até um certo limite. $O$ excedente de consumo deve ser atendido pela produção da região integrada.

Um aspecto, que merece ser destacado, é que o trabalho exclui as tecnologias e as produções de lavouras cultivadas na forma de consorciações (agricultura camponesa), desconsiderando, portanto, os recursos disponiveis às mesmas. Portanto, da mesma forma, foram subtraídas das demandas regionais por produtos, os volumes atendidos por estas lavouras.

Para identificar tendências na realocação das culturas e nos fluxos de comércio, gerados pela integração, foram consideradas diversas fases progressivas do processo de integração, sem que estas sejam necessariamente as etapas que na realidade deverão ocorrer.

Estas fases são:

Integraçāo Fase I - Cria-se uma área de livre comércio entre os 
palses. Impede-se a importação dos produtos considerados de terceiros palses, levando-se a regiāo integrada a $100 \%$ do auto-abastecimento. Cada pals, em separado, mantém seus compromissos de exportação com o resto do mundo.

Integraçāo Fase II - Esta somente se diferencia da fase I, por unir os compromissos de exportação dos dois paises. As diferentes regiōes dos dois palses passam a concorrer entre si para o atendimento da demanda por exportações.

Integraçāo Fase III - Esta se diferencia da fase II, por apresentar liberadas as importações de terceiros paises, passando, portanto, a produção da região integrada a concorrer com o mercado mundial para o seu abastecimento.

\section{CUSTOS DE PRODUÇÃO}

Neste item apresenta-se a análise dos custos de produção do trigo, do milho, da soja e do arroz nas regiōes e palses abrangidos pelo estudo. Comparam-se as dimensões e as estruturas dos custos de produção, tanto entre os estados considerados no Brasil, como entre estes e a Argentina.

\subsection{Trigo}

O custo de produção do trigo no Brasil é de US\$235,50 por tonelada (média ponderada pelos volumes de produção dos estados inclúldos no estudo).

Os estados do Rio Grande do Sul e Paraná apresentam custos de produção inferiores aos dos estados de São Paulo e Mato Grosso do Sul (ver tabela 1). As diferenças são devidas aos custos variáveis, principalmente com sementes, fertilizantes, pesticidas e transporte externo.

Com relação às sementes, por serem menores os rendimentos tisicos, principalmente em São Paulo, as doses por tonelada de produto obtidos são maiores. Além disso, os preços são superiores, possivelmente pelos menores volumes comercializados e a menor especialização do respectivo complexo de produção.

Também são evidentes as diferenças nos custos com calcário e fertilizantes. Estas são devidas aos menores rendimentos físicos em 
São Paulo e aos maiores preços dos insumos e às maiores quantidades aplicadas por tonelada de produto no Mato Grosso do Sul.

O baixo rendimento físico, obtido no estado de São Paulo, eleva também os custos unitários com pesticidas.

As despesas com transporte entre a unidade de produção e o primeiro centro de compra-venda de produtos e insumos encarecem a produção de Mato Grosso do Sul e reduzem os custos da de São Paulo, devido, respectivamente, às maiores e menores distâncias.

A comparação de custos Brasil-Argentina mostra diferenças muito grandes. Os custos da Argentina, de US $\$ 71,00$ por tonelada, correspondem a $30 \%$ dos brasileiros.

Estas diferenças são devidas a dois tipos de fatores: as melhores condições de solo e clima e o sistema de produção. As condiçōes de solo e clima são responsáveis pelo menor uso de calcário, fertilizantes e pesticidas na produção do trigo argentino. Enquanto que, no Brasil, estes insumos têm uma participação de mais de $40 \%$ no custo total, na Argentina, participam com apenas 7,3\%.

Os custos argentinos com calcário, fertilizantes e pesticidas na produção da tonelada de trigo correspondem a, aproximadamente, $5 \%$ dos custos brasileiros com os mesmos insumos.

As despesas argentinas com sementes, por tonelada de produto obtido, correspondem a $30 \%$ das brasileiras, principalmente devido ao maior rendimento por unidade de área.

$\mathrm{Na}$ Argentina, a colheita é, principalmente, contratada junto a empresas especializadas, e a aplicação de defensivos agrlcolas é feita via aérea. Este sistema de produção permite que as empresas operem com menor estoque de capital (maquinária) e mão-de-obra permanente. Este fato, aliado ao maior rendimento f́sico por unidade de área, resulta em menores custos fixos por unidade de produto. Os custos fixos argentinos por tonelada de trigo "equivalem a, aproximadamente, $40 \%$ dos brasileiros.

Os custos de transporte de insumos e do produto, ou até o primeiro ponto de compra-venda, são significativamente menores na Argentina (12\% dos do Brasil). Isto se explica pelas menores distâncias até o mercado, menores tarifas dos serviços de transporte e menores cargas totais de insumos a transportar em relação à tonelada de produto.

O custo de produção do trigo (excluindo o custo da terra) nos Estados Unidos é de US\$132,81, no Canadá e de US\$124,41, no Reino Unido é de US $\$ 111,26$ e na Austrália é de US\$93,92, segundo estima- 
tivas de ORTMANN, G., STULP, V.J. e RASK, N. (1986). Estes valores mostram um grande hiato dos custos de produção da Argentina, em relação aos dos seus concorrentes no mercado internacional. Este pals, portanto, conta com condições favoráveis para manter e ampliar as suas vantagens comparativas e a sua competitividade na produção deste cereal.

\section{TABELA 1}

Trigo: Composição dos Custos de Produção em Quatro Estados do Brasil e no Pampa Argentino*

\begin{tabular}{|c|c|c|c|c|c|c|c|c|c|c|}
\hline \multirow[t]{2}{*}{ ITEM } & & \multicolumn{2}{|l|}{ PR } & & & \multicolumn{2}{|c|}{$\begin{array}{r}\text { Pampa } \\
\text { Argentino }\end{array}$} \\
\hline & Custo & $\%$ & Custo & $\%$ & Custo & $\%$ & Custo & $\%$ & Custo & $\%$ \\
\hline CUSTO TOTAL (US\$) & 224 & & 234 & & 265 & & 263 & & 71 & \\
\hline$(\mathrm{Cz} \$)$ & 9845 & 100 & 10277 & 100 & 11630 & 100 & 11558 & 100 & 3119 & 100 \\
\hline I-CUSTOS VARIÁVEIS & 7694 & 78,2 & 8044 & 78,3 & 9355 & 80,4 & 9499 & 82,2 & 2173 & 68,7 \\
\hline $\begin{array}{l}\text { 1-Măo-de-obra } \\
\text { 2-Conservaçăo e }\end{array}$ & 60 & 0,6 & 63 & 0,6 & 73 & 0,6 & 49 & 0,4 & 194 & 6,2 \\
\hline $\begin{array}{l}\text { reparos } \\
\text { 3-Combustlveis, lubrif., }\end{array}$ & 634 & 6,4 & 605 & 5,9 & 581 & 5,0 & 563 & 4,9 & 212 & 6,8 \\
\hline filtros & 710 & 7,2 & 670 & 6,5 & 748 & 6,4 & 702 & 6,0 & 239 & 7,7 \\
\hline $\begin{array}{l}\text { 4-Sementes } \\
\text { 5-Calcário e fertili- }\end{array}$ & 1127 & 11,4 & 1408 & 13,7 & 1626 & 14,0 & 2255 & 19,5 & 482 & 15,5 \\
\hline zantes & 2357 & 23,9 & 2422 & 23,6 & 2993 & 25,8 & 2616 & 22,6 & 98 & 3,1 \\
\hline 6-Pesticidas & 1726 & 17,6 & 1848 & 18,0 & 1969 & 17,0 & 2539 & 22,0 & 131 & 4,2 \\
\hline 7-Transporte extemo & 482 & 4,9 & 578 & 5,6 & 897 & 7,7 & 307 & 2,7 & 68 & 2,2 \\
\hline $\begin{array}{l}\text {-Recepçao, secagem, } \\
\text { limpeza }\end{array}$ & 207 & 2,1 & 207 & 2,0 & 219 & 1,9 & 208 & 1,8 & 13 & 0,4 \\
\hline $\begin{array}{l}\text { 9-Colheita contratada } \\
\text { 10-Outros insumos e }\end{array}$ & - & - & - & - & - & - & - & - & 608 & 19,5 \\
\hline serviços & 220 & 2,2 & 35 & 0,3 & 47 & 0,4 & 41 & 0,4 & 92 & 2,9 \\
\hline 11-Juros sobre cap.giro & 171 & 1,7 & 177 & 1,7 & 201 & 1,7 & 219 & 1,9 & 36 & 1,2 \\
\hline II-CUSTOS FIXOS & 2151 & 21,8 & 2233 & 21,7 & 2275 & 19,6 & 2059 & 17,8 & 946 & 30,3 \\
\hline 1-Mão-de-obra & 475 & 4,8 & 503 & 4,9 & 432 & 3,7 & 479 & 4,1 & 163 & 5,2 \\
\hline 2-Depreciaçס̄es & 809 & 8,2 & 787 & 7,6 & 943 & 8,1 & 745 & 6,5 & 400 & 12,8 \\
\hline 3-Seguros & 51 & 0,5 & 52 & 0,5 & 56 & 0,5 & 47 & 0,4 & 23 & 0,7 \\
\hline 4-Juros sobre cap.fixo & 816 & 8,3 & 891 & 8,7 & 844 & 7,3 & 788 & 6,8 & 360 & 11,6 \\
\hline RENDIMENTOS (t/ha) & 1,5 & & 1,56 & & 1,46 & & 1,14 & & 2,30 & \\
\hline
\end{tabular}

Obs: Os dados săo em dólares e em cruzados do més de junho de 1987, por tonelada de produto comercial.

FONTES: Dados da Pesquisa. 
Por outro lado, a produção brasileira, no curto prazo ao menos, sø pode subsistir amparada em consideráveis barreiras ao comércio. Assim, enquanto o custo de produção no Brasil é de US $\$ 235,5 /$ t, o preço de fronteira, com origem do produto nos Estados Unidos, é de US\$ 140,51 CIF Brasil (média 1985-87).

No longo prazo, resta verificar se alternativas tecnológicas conseguem reduzir este custo de produção brasileiro.

\subsection{Milho}

Os quatro estados brasileiros cobertos pela pesquisa respondem por $55,8 \%$ da produção e $46 \%$ da área colhida com milho no Brasil. 0 custo médio de produção é de aproximadamente US\$ 88,30/t (ponderado pelos volumes da produção estadual no qüinqüênio 1982-86).

São Paulo apresenta o menor custo (US\$ 77,00/t) em conseqüência do menor uso de calcário e pesticidas, menores despesas com transporte, menor depreciação e juros sobre o capital fixo. Estes dois últimos itens são de menor valor devido ao uso mais intensivo do capital, o que reduz o custo da hora utilizada.

Mato Grosso do Sul apresenta o maior custo (US\$ 116,00/t) associado às maiores despesas corn fertilizantes e calcário e consideráveis custos com transporte externo.

No Mato Grosso do Sul, a produção vem se deslocando das pequenas propriedades da região de matas para unidades maiores com níveis mais elevados de tecnologia, em rotação com a soja. Assim, os estímulos para a cultura da soja também favorecem a cultura do milho (SIBAN; 1987).

Paraná e Rio Grande do Sul apresentam custos de produção do milho intermediários entre os de São Paulo e Mato Grosso do Sul. Este Estado, e o Centro-Oeste de uma maneira geral, apesar dos altos custos, apresenta o maior dinamismo na expansão desta cultura. Isto talvez se explique, em parte, pelo menor custo de oportunidade da terra nestas regiōes em comparação com o Sudeste e o Sul. Recorde-se que o custo da terra não está incluldo nos custos totais de produção apresentados neste estudo.

O custo de produção do milho na Argentina é de US\$ 60,90/t, ou seja, igual a aproximadamente $69 \%$ do custo brasileiro. A explicação para este menor custo argentino reside na fertilidade natural do solo, onde 
é possivel obter-se alta produtividade com o mínimo de aplicação de fertilizante.

\section{TABELA 2}

\section{Milho: Composição dos Custos de Produção em Quatro Estados do Brasil e no Pampa Argentino*}

\begin{tabular}{|c|c|c|c|c|c|c|c|c|c|c|}
\hline \multirow[t]{2}{*}{ ITEM } & \multicolumn{2}{|l|}{ RS } & & & \multicolumn{2}{|l|}{ SP } & \multicolumn{2}{|c|}{$\begin{array}{r}\text { Pampa } \\
\text { Argentino }\end{array}$} \\
\hline & Custo & $\%$ & Custo & $\%$ & Custo & $\%$ & Custo & $\%$ & Custo & $\%$ \\
\hline CUSTO TOTAL (US\$) & 84 & & 97 & & 116 & & 77 & & 61 & \\
\hline$(\mathrm{Cz} \$)$ & 3669 & 100 & 4237 & 100 & 5102 & 100 & 3359 & 100 & 2671 & 100 \\
\hline I-CUSTOS VARIÁVEIS & 2562 & 69,8 & 3243 & 76,5 & 3866 & 75,8 & 2401 & 71,5 & 1750 & 65,5 \\
\hline $\begin{array}{l}\text { 1-Måo-de-obra } \\
\text { 2-Consérvaçăo e }\end{array}$ & 69 & $1, \dot{9}$ & 395 & 9,3 & 39 & 0,8 & 40 & 1,2 & 148 & 5,5 \\
\hline reparos & 349 & 9,5 & 183 & 4,3 & 355 & 7,0 & 244 & 7,3 & 203 & 7,6 \\
\hline $\begin{array}{l}\text { 3-Combustiveis, lubrif., } \\
\text { filtros }\end{array}$ & 311 & 8,5 & 366 & 8,6 & 456 & 8,9 & 419 & 12,5 & 175 & 6,6 \\
\hline $\begin{array}{l}\text { 4-Sementes } \\
\text { 5-Calcário e fertili- }\end{array}$ & 143 & 3,9 & 138 & 3,3 & 170 & 3,3 & 226 & 6,7 & 460 & 17,2 \\
\hline zantes & 771 & 21,0 & 1191 & 28,1 & 1734 & 34,0 & 1025 & 30,5 & 3 & 0,1 \\
\hline 6-Pesticidas & 317 & 8,6 & 302 & 7,1 & 94 & 1,8 & - & - & 144 & 5,4 \\
\hline $\begin{array}{l}\text { 7-Transporte externo } \\
\text { 8-Recepçăo, Secagem, }\end{array}$ & 421 & 11,5 & 476 & 11,3 & 811 & 15,9 & 270 & 8,0 & 67 & 2,5 \\
\hline limpeza & 128 & 3,5 & 128 & 3,0 & 136 & 2,7 & 128 & 3,8 & 75 & 2,8 \\
\hline $\begin{array}{l}\text { 9-Colheita contratada } \\
10-\text { Outros insumos e }\end{array}$ & - & - & - & - & - & - & - & - & 447 & 16,7 \\
\hline serviços & 4 & 0,1 & - & - & - & - & - & - & - & - \\
\hline 11-Juros sobre cap.giro & 49 & 1,3 & 64 & 1,5 & 71 & 1,4 & 49 & 1,5 & 28 & 1,1 \\
\hline II-CUSTOS FIXOS & 1107 & 30,2 & 994 & 23,5 & 1236 & 24,2 & 958 & 28,9 & 921 & 34,5 \\
\hline 1-Măo-de-obra & 199 & 5,4 & 312 & 7,4 & 224 & 4,4 & 244 & 7,3 & 232 & 8,7 \\
\hline 2-Depreciaçס̄es & 439 & 12,0 & 300 & 7,1 & 506 & 9,9 & 343 & 10,2 & 342 & 12,8 \\
\hline 3-Seguros & 29 & 0,8 & 20 & 0,5 & 31 & 0,6 & 21 & 0,6 & 20 & 0,8 \\
\hline 4-Juros sobre cap.fixo & 440 & 12,0 & 362 & 8,5 & 475 & 9,3 & 350 & 10,4 & 327 & 12,2 \\
\hline RENDIMENTOS (tha) & 3,50 & & 3,00 & & 3,00 & & 3,00 & & 4,00 & \\
\hline
\end{tabular}

Obs: Os dados såo em dólares e em cruzados do més de junho de 1987, por tonelada de produto comercial.

FONTES: Dados da Pesquisa. 


\subsection{Soja}

Os custos de produção da soja na área abrangida por este estudo, no Brasil, são iguais a US\$ 154,40/t (média ponderada pelos volumes de produção estadual). O maior custo é o do Mato Grosso do Sul (US\$ $183,00 / t)$, Estado responsável no qüinqüênio $1982-86$ por $13,2 \%$ da produção nacional. Neste Estado, a cultura tern-se expandido aceleradamente, em parte,-devido à sua maior rentabilidade em comparação com as outras culturas.

A diferença entre o custo de produção do Mato Grosso do Sul e os dos demais estados é devida principalmente às maiores despesas com fertilizantes, pesticidas e transporte externo. A cultura concentra-se em áreas de campos e cerrados, demandando maior quantidade de calcário e fertilizantes (SIBAN, 1987). Devido a estas maiores cargas de insumos a transportar e às maiores distâncias, os custos com o transporte externo são elevados.

São Paulo, responsável no qüinqüênio $1982-86$ por $6,3 \%$ da produção nacional, apresenta o menor custo de produção (US $\$ 139,00 / t)$. Menores despesas com pesticidas e com transporte externo são as causas principais do custo mais baixo.

Os estados do Paraná e Rio Grande do Sul apresentarn custos de produção intermediários, com valores totais e estruturas muito semeIhantes entre um e outro (tabela 3). No entanto, o rendimento por unidade de área é maior no Rio Grande do Sul do que no Paraná.

$\mathrm{Na}$ década de 1980, a cultura se manteve relativamente estável nos estados da Região Sul e São Paulo, enquanto ocorreu uma expansão no Mato Grosso do Sul e, em geral, no Centro-Oeste. Estas tendências não parecem coerentes com os custos de produção. No entanto, deve-se observar que as culturas competem pela ocupação de determinado espaço, através da remuneração que comparativarmente oferecem pelo uso dos recursos, dado um determinado desenvolvimento tecnológico, infra-estrutural, etc. Sob esta ótica, o estancamento em São Paulo, por exemplo, pode-se explicar pelo fato da soja competir com culturas que remuneram melhor os fatores de produção.

No Mato Grosso do Sul, onde os custos de produção são maiores, o avanço da soja está associado à sua posição frente às outras atividades técnica e, economicamente, viáveis. Assim, o desestímulo à expansão de pastagens, a inexistência de alternativas mais rentáveis nas 
áreas inicialmente ocupadas pelo arroz e a segurança na comercialização têm atuado como estímulo à expansão da soja na região.

TABELA 3

Soja: Composição dos Custos de Produção em Quatro Estados do Brasil e no Pampa Argentino*

\begin{tabular}{|c|c|c|c|c|c|c|c|c|c|c|}
\hline \multirow{2}{*}{ ITEM } & & & & & \multicolumn{2}{|c|}{$\begin{array}{r}\text { Pampa } \\
\text { Argentino }\end{array}$} \\
\hline & Custo & $\%$ & Custo & $\%$ & Custo & $\%$ & Custo & $\%$ & Custo & $\%$ \\
\hline CUSTO TOTAL (US\$) & 149 & & 151 & & 183 & & 139 & & 114 & \\
\hline$(\mathrm{Cz} \$)$ & 6552 & 100 & 6608 & 100 & 8030 & 100 & 6090 & 100 & 4992 & 100 \\
\hline I-CUSTOS VARIÁVEIS & 4690 & 71,6 & 4802 & 72,7 & 6403 & 79,7 & 4372 & 71,8 & 3383 & 67,8 \\
\hline $\begin{array}{l}\text { 1-Mão-de-obra } \\
\text { 2-Conservação e }\end{array}$ & 83 & 1,3 & 77 & 1,2 & 50 & 0,6 & 67 & 1,1 & 287 & 5,7 \\
\hline $\begin{array}{l}\text { reparos } \\
3 \text {-Combustiveis, lubrif., }\end{array}$ & 585 & 8,9 & 514 & 7,8 & 452 & 5,6 & 463 & 7,6 & 356 & 7,1 \\
\hline filtros & 609 & 9,3 & 582 & 8,8 & 638 & 7,9 & 653 & 10,7 & 332 & 6,7 \\
\hline $\begin{array}{l}\text { 4-Sementes } \\
\text { 5-Calcário e fertili- }\end{array}$ & 756 & 11,6 & 619 & 9,4 & 853 & 10,6 & 736 & 12,1 & 719 & 14,4 \\
\hline zantes & 1464 & 22,4 & 1430 & 21,6 & 2160 & 26,9 & 1490 & 24,5 & - & - \\
\hline 6-Pesticidas & 480 & 7,3 & 869 & $13 ; 2$ & 1043 & 13,0 & 381 & 6,3 & 323 & 6,4 \\
\hline 7-Transporte externo & 511 & 7,8 & 515 & 7,8 & 965 & 12,0 & 372 & 6,1 & 69 & 1,4 \\
\hline $\begin{array}{l}\text { 8-Recepção, Secagem, } \\
\text { limpeza }\end{array}$ & 94 & 1,4 & 94 & 1,4 & 100 & 1,3 & 94 & 1,5 & 55 & 1,1 \\
\hline $\begin{array}{l}\text { 9-Colheita contratada } \\
10 \text {-Outros insumose }\end{array}$ & - & - & - & - & - & - & - & - & 1061 & 21,3 \\
\hline serviços & 8 & 0,1 & - & - & 12 & 0,2 & 21 & 0,3 & 128 & 2,6 \\
\hline 11-Juros sobre cap.giro & 100 & 1,5 & 102 & 1,5 & 130 & 1,6 & 95 & 1,6 & 53 & 1,1 \\
\hline \|-CUSTOS FIXOS & 1862 & 28,4 & 1806 & 27,3 & 1627 & 20,3 & 1718 & 28,2 & 1610 & 32,2 \\
\hline 1-Măo-de-obra & 412 & 6,3 & 388 & 5,9 & 282 & 3,5 & 390 & 6,4 & 372 & 7,4 \\
\hline 2-Depreciaçס̄es & 694 & 10,6 & 652 & 9,9 & 682 & 8,5 & 648 & 10,6 & 622 & 12,5 \\
\hline 3-Seguros & 44 & 0,7 & 44 & 0,6 & 41 & 0,5 & 40 & 0,7 & 37 & 0,7 \\
\hline 4-Juros sobre cap.fixo & 712 & 10,8 & 722 & 10,9 & 622 & 7,8 & 640 & 10,5 & 579 & 11,6 \\
\hline RENDIMENTOS (t/ha) & 1,62 & & 2,10 & & 2,16 & & 1,80 & & 2,50 & \\
\hline
\end{tabular}

Obs: Os dados săo em dólares e em cruzados do més de junho de 1987, por tonelada de produto comercial.

FONTES: Dados da Pesquisa. 
O Instituto Brasileiro de Economia (FGV) em Retrospectiva Agropecuária 1985 coloca: “... é preciso ressaltar que, no caso da soja, o deslocamento da produção para a região Centro-Oeste é uma questão problemática... para manter-se viável a produção naquela região, é preciso que seus ganhos em produtividade física mais do que compensem os elevados custos do frete aos centros de processamento e aos portos de exportação. $\mathrm{Na}$ safra 85, o governo federal acabou adquirindo algo próximo a 2 milhões de toneladas de soja nesta região". Assim, a expansão da soja para o Centro-Oeste se explicaria não só pelos custos de oportunidade menores da terra, mas também por políticas governamentais visando a incorporação da região à economia nacional.

Comparando-se o custo de produção da soja por unidade de área no Brasil com o da Argentina, verifica-se que eles são praticamente iguais. Porém, devido ao maior rendimento por área na Argentina, o custo de produção da tonelada de soja argentina corresponde a $74 \%$ do custo da tonelada de soja brasileira (tabela 5).

O fator básico para o menor custo de produção na Argentina é a fertilidade natural do solo que permite altos rendimentos, sem utilizar fertilizantes. Contribuem ainda para esta diferença as menores despesas argentinas com o transporte externo, devido, principalmente, às pequenas quantidades de insumos a transportar.

\subsection{Arroz}

Os dados de custo da produção de arroz no Brasil se referem a dois sistemas de produção diferentes. Um, é o do arroz produzido sob condições de irrigação no Rio Grande do Sul, com altos rendimentos. $O$ custo, neste sistema, é de US\$135,00/t. O outro sistema é o do arroz de sequeiro, referente aos outros estados, em que o custo é de US\$ $163,00 /$ t.

Em termos de vantagens de produção no mercado interno, é clara a do Rio Grande do Sul. Porém mais da metade da produção nacional ainda é produzida nas condições de sequeiro. Isto reflete, em parte, 0 fato de que as culturas de sequeiro são típicas de abertura de novas áreas, processo no qual o produtor não visa maximizar lucro no curto prazo, senão minimizar os custos de adequação das terras. Além disto, em muitas áreas, a irrigaşão não é técnica ou economicamente viável, mas, ainda assim, o arroz pode ser uma das culturas de maior rentabilidade. 
A comparação entre os custos de produção do Rio Grande do Sul e da Argentina (US $\$ 178,70 / t$ ), referentes ao arroz irrigado nos dois casos, mostra a vantagem do Brasil. A principal causa da diferença é decorrente do maior custo com máquinas e combustiveis na Argentina, por ser a irrigação feita a partir de poços profundos.

\section{TABELA 4}

\section{Arroz: Composição dos Custos de Produção em Quatro Estados do Brasil e no Pampa Argentino*}

\begin{tabular}{|c|c|c|c|c|c|c|c|c|c|c|}
\hline \multirow[t]{2}{*}{ ITEM } & \multicolumn{2}{|l|}{ RS } & & & & \multicolumn{2}{|c|}{$\begin{array}{r}\text { Pampa } \\
\text { Argentino }\end{array}$} \\
\hline & Custo & $\%$ & Custo & $\%$ & Custo & $\%$ & Custo & $\%$ & Custo & $\%$ \\
\hline $\begin{array}{r}\text { USTO TOTAL. (US\$) } \\
\text { (CZ\$) }\end{array}$ & $\begin{array}{l}135 \\
5929\end{array}$ & 100 & $\begin{array}{l}151 \\
6619\end{array}$ & 100 & $\begin{array}{l}189 \\
8303\end{array}$ & 100 & $\begin{array}{l}147 \\
6446\end{array}$ & 100 & $\begin{array}{l}179 \\
7844\end{array}$ & 100 \\
\hline I-CUSTOS VARI & 4039 & 68,1 & 47 & 72,0 & 6423 & 77,4 & 17 & 71,6 & 4651 & 59,3 \\
\hline $\begin{array}{l}\text { 1-Măo-de-obra } \\
\text { 2-Conservaçăo e }\end{array}$ & 3 & 5,4 & 42 & 0,6 & 79 & 1,0 & 207 & 3,2 & 31 & 4,0 \\
\hline $\begin{array}{l}\text { reparos } \\
\text { 3-Combustiveis, lubrif., }\end{array}$ & 711 & 12,0 & 604 & 9,1 & 577 & 7,0 & 369 & 5,7 & 1094 & 13,9 \\
\hline filtros & 1151 & 19,4 & 691 & 10,4 & 742 & 8,9 & 877 & 13,6 & 15 & 20,2 \\
\hline $\begin{array}{l}\text { 4-Sementes } \\
\text { 5-Calcário e fertill- }\end{array}$ & 439 & 7,4 & 410 & 6,2 & 808 & 9,7 & 344 & 5,3 & 690 & 8,8 \\
\hline zantes & 628 & 10,6 & 1713 & 25,9 & 2363 & 28,5 & 2093 & 32,5 & 8 & 1,1 \\
\hline 6-Pesticidas & 352 & 5,9 & 487 & 7,4 & 811 & 9,8 & - & - & 527 & 6,7 \\
\hline $\begin{array}{l}\text { 7-Transporte externo } \\
\text { 8-Receptato, Secagem, }\end{array}$ & 219 & 3,7 & 526 & 8,0 & 681 & 8,2 & 422 & 6,6 & 95 & 1,2 \\
\hline limpeza & 71 & 1,2 & 187 & 2,8 & 219 & 2,6 & 187 & 2,9 & 159 & 2,0 \\
\hline $\begin{array}{l}\text { 9-Colheita contratada } \\
\text { 10-Outros insumos e }\end{array}$ & - & - & - & - & - & - & - & - & - & . \\
\hline serviç & 60 & 1,0 & 5 & 0,1 & 8 & 0,1 & 20 & 0,3 & - & . \\
\hline 11-Juros sobre ce & 91 & 1,5 & 99 & 1,5 & 135 & 1,6 & 98 & 1,5 & 108 & 1,4 \\
\hline II-cus & 1890 & 31,9 & 1855 & 28,0 & 1880 & 22,6 & 1829 & 28,4 & & 40,7 \\
\hline $1-M$ & & 6,1 & 31 & 4,8 & & 4,0 & 507 & 7,9 & & 7,7 \\
\hline 2-Depreciaçбes & 773 & 13,0 & 743 & 11,2 & 760 & 9,2 & 645 & 10,0 & 1469 & 18,7 \\
\hline $3-\mathrm{Sec}$ & 33 & 0,6 & 48 & 0,7 & 49 & 0,6 & 38 & 0,6 & 73 & 0,9 \\
\hline 4-Juros sobre cap.fixo & 725 & 12,2 & 748 & 11,3 & 735 & 8,8 & 639 & 9,9 & 1051 & 13,4 \\
\hline RENDIMENTOS (t/ha) & 4,51 & & 1,80 & & 1,44 & & 1,62 & & 4,50 & \\
\hline
\end{tabular}

Obs: Os dados săo em dólares e em cruzados do mês de junho de 1987, por tonelada de produto comencial.

FONTES: Dados da Pesquisa. 
TABELA 5

Custos de Produção do Trigo, Milho, Soja e Arroz no Brasil e Argentina

\begin{tabular}{lrlll}
\hline País & Trigo & Milho & Soja & Arroz \\
\hline Brasil $^{\star}$ & 235,50 & 88,30 & 154,40 & 135,50 \\
Argentina & 71,10 & 60,90 & 113,80 & 178,70 \\
\hline
\end{tabular}

Obs.: a) Os dados são em dólares de junho de 1987:

$\left.b^{*}\right)$ Os custos do Brasil são custos médios ponderados pelos volumes de produção dos estados do RS, PR, SP, MS.

FONTE: Dados da Pesquisa.

\section{VANTAGENS ABSOLUTAS E COMPARATIVAS NA PRODUÇÃO}

A Argentina apresenta vantagens absolutas de custos na produção de trigo, milho e soja; e o Brasil, na de arroz. Em termos de vantagens comparativas, poder-se-ia afirmar, por exemplo, que a Argentina deveria se especializar na produção do trigo. Com os mesmos recursos que necessita para produzir uma tonelada de trigo, ela poderia produzir, alternativamente, ou $1168 \mathrm{Kg}$ de milho, ou $625 \mathrm{Kg}$ de soja, ou então $397 \mathrm{Kg}$ de arroz. Mas se a Argentina se especializasse na produção de trigo, poderia obter em cada tonelada deste, mediante troca por produtos brasileiros, até $2666 \mathrm{Kg}$ de milho, até $1525 \mathrm{Kg}$ de soja ou até $1738 \mathrm{Kg}$ de arroz, com claras vantagens sobre a produção própria.

O Brasil, de acordo com esse mesmo conceito, deveria deixar de produzir trigo e especializar-se na produção de arroz, trocando-o por trigo. Assim, o Brasil, em cada $575 \mathrm{Kg}$ de trigo que deixe de produzir, ao aplicar estes recursos na produção de arroz, obteria $1000 \mathrm{Kg}$ de arroz que, trocados por produtos argentinos, permitiriam obter até $2513 \mathrm{Kg}$ de trigo, ou até $2934 \mathrm{Kg}$ de milho, ou até $1570 \mathrm{Kg}$ de soja.

Há evidentes limitações na aplicação das vantagens comparativas. Assim, por exemplo:

- Não é considerada a mobilidade dos recursos, especialmente da terra, no espaço (de uma região para outra) e nem no tempo (do inverno 
para o verão). Onde se produz trigo no Rio Grande do Sul, não se produz arroz, e vice-versa. O trigo é cultura de inverno e o arroz é cultura de verão.

- Não é considerada a limitação de mercado. O consumo de arroz na Argentina é muito pequeno, correspondendo a menos de $5 \%$ da produção brasileira.

- Não são incluídas, na análise, prováveis mudanças nos custos de oportunidade dos recursos em função de uma maior ou menor produçāo de determinado produto. produtos.

- Não são considerados, acima, os custos de transferência dos

Por isto, a análise dos impactos da integração Brasil-Argentina é realizada, neste estudo, através do conceito de competitividade que engloba todos os aspectos acima mencionados.

\section{LIBERAÇĀO DO COMÉRCIO BRASIL-ARGENTINA E A REALOCAÇÃO DA PRODUÇÃO AGRÍCOLA}

Como já foi visto, a análise considera três fases progressivas da integração econômica entre os dois palses.

\section{Fase I}

Na primeira fase, simula-se a abolição das taxas alfandegárias ao comércio dos produtos de interesse entre os dois países. Simultaneamente, impede-se a importação dos quatro produtos de terceiros países, hevando-se a regiāo integrada ao total auto-abastecimento. Cada país mantém seus compromissos de exportação para terceiros países.

A liberação do comércio Brasil-Argentina, em relação aos quatro produtos considerados, gera fluxos de comércio da Argentina para o Brasil, implicando modificações drásticas na estrutura de abastecimento do trigo e, em menor dimensão, da soja.

Com relação ao milho e arroz, o Brasil mostra-se competitivo frente à Argentina, para o abastecimento de seu próprio mercado interno.

A redução na produção brasileira de trigo seria de $42 \%$. A produção deste cereal praticamente desapareceria nós estados do Rio Grande do Sul, São Paulo e Mato Grosso do Sul, permanecendo apenas no estado do Paraná. Neste estado, haveria redução de $26 \%$ na produção. O Rio Grande do Sul, apesar do menor custo de produção, perde em 
competitividade para o Paraná, devido à melhor localização deste ęstado em relação aos mercados do sudeste do país.

A produção brasileira de soja diminuiria em $34 \%$ como resultado da primeira fase de integração. A soja que deixa de ser produzida no Brasil é importada da Argentina; que aumenta sua produção em quase $90 \%$.

A maior queda na produção da soja ocorreria no estado do Mato Grosso do Sul onde praticamente desaparece ante a concorrência do produto argentino. No Rio Grande do Sul, a queda seria de $16 \%$ e de somente $3 \%$ no Paraná.

Não há mudança nos volumes totais do Brasil e Argentina na produção de milho e arroz, na fase I. Portanto, o milho argentino não é competitivo no mercado brasileiro e nem o arroz brasileiro o é no mercado argentino. As diferenças entre os custos de produção (incluindo agora o custo de oportunidade do fator fixo terra) não compensam os custos da transferência do produto. Além disto, o consumo de arroz na Argentina es muito reduzido.

Ocorrem apenas realocações estaduais da produção de milho e arroz. Há deslocamento da produção de milho do Mato Grosso do Sul para o Rio Grande do Sul, onde ela aumenta em $5 \%$ ocupando áreas liberadas pela soja.

A produção de arroz do Mato Grosso do Sul diminui na fase I, limitando-se ao volume de sua demanda regional, nivel de produção que se mantém constante nas outras fases de integração consideradas. Este decréscimo é compensado pelo estado do Paraná.

Portanto, o impacto maior da integração na fase l ocorre no estado do Mato Grosso do Sul, onde haveria reduçōes drásticas na produção de trigo, soja, milho e, em menor dimensão, do arroz. Isto é devido aos maiores custos de produção neste Estado e à magnitude da barreira imposta pelos altos custos de transporte que dificultam a salda da produção.

\section{Fase II}

Nesta fase, as demandas por exportações dos dois palses são unificadas, passando estes e os estados a competirem para o atendimento destas demandas.

Em relação ao trigo, não há nenhuma mudança da fase I para a fase II, já que o Brasil não é exportador de trigo.

Em relação à soja, a Argentina se mostra mais competitiva no 
mercado externo do que o Brasil. Assim, os compromissos brasileiros de exportação da soja em grão são atendidos pela Argentina. Esta, por sua vez, ao aumentar as suas exportações para terceiros paises, reduz as exportações para o Brasil. O resultado líquido desta troca é um aumento na produção brasileira de soja de $2 \%$ e uma redução de $2 \%$ na produção Argentina, da fase I para a fase II.

No atendimento da demanda por exportaçóes, a Argentina se mostra mais competitiva no milho e o Brasil, no arroz. A lavoura de milho para exportação se desloca para a Argentina e a de arroz para o Brasil. Porém, estes deslocamentos não têm maiores significados pela pequena dimensão das exportações brasileiras de milho e das argentinas de arroz.

A redução na produção brasileira de milho ocorre no Rio Grande do Sul, enquanto a de arroz aumenta no Paraná. O arroz gaúcho substitui as exportações argentinas com uma parcela das remessas que faz ao centro do país. A terra e a água restringem uma maior expansão do arroz irrigado no Rio Grande do Sul. A parcela que deixa de ser enviada pelo Rio Grande do Sul é substituída pelo Paraná geograficamente melhor situado em relação a São Paulo e Rio de Janeiro e que, assim, aumenta a sua produção.

\section{Fase III}

Nesta fase, são liberadas as importações de terceiros paĺses.

A produção brasileira de trigo que se registra na fase ll é totalmente substitulda, na fase III, por produto importado de terceiros países. Nesta fase, $75 \%$ do consumo brasileiro de trigo é atendido pela Argentina e $25 \%$ por terceiros paises. Na realidade, a participação do trigo argentino no abastecimento brasileiro poderia ser maior na medida em que a Argentina reduzisse seus compromissos de exportação para terceiros paises. Isto se torna evidente por que os $25 \%$ de trigo que o Brasil importa de terceiros palses tem preço de fronteira mais alto do que o trigo argentino.

Da fase II para a fase III, não ocorre nenhuma mudança nos volumes totais de produção, brasileiros e argentinos, de soja. A liberação das importações de milho e arroz, a partir de terceiros países, também não produz nenhuma mudança nos fluxos de comércio entre Brasil e Argentina nem realocação da produção entre estados. Isto significa que o arroz, milho e soja do mercado mundial não seriam competitivos nos mercados internos integrados do Brasil e Argentina. 


\section{A COMPETITIVIDADE E MEDIDAS DE POLITICA}

Neste item, analisam-se algumas condições sob as quais a produção brasileira poderia ser competitiva em relação à argentina. Estas condições refletiriam mudanças na eficiência produtiva de transporte e/ou em medidas de política econômica que atenuariam os efeitos da integração.

Os problemas de competitividade do Brasil frente à Argentina podem ser agrupados por produto e por região. Quanto aos produtos, constatou-se que o trigo e a soja apresentam problemas de competitividade. O primeiro, num hiato tal de custo, que a produção nacional tenderia a um rápido desaparecimento e, com relação à soja, sendo menores as diferenças de custos, a produção brasileira seria reduzida em aproximadamente um terço do seu nivel atual.

$\mathrm{Na}$ dimensão regional, a integração causaria efeitos drásticos no Mato Grosso do Sul onde a produção comercial dos produtos considerados praticamente desapareceria.

Assim, analisa-se:

- em relação a produtos, o impacto de taxas alfandegárias sobre as importações de soja da Argentina. Deixa-se de analisar o impacto destas taxas sobre o trigo devido ao grande hiato entre os custos de produção deste cereal entre os dois paises. Assim dificilmente taxas alfandegárias em níveis razoáveis teriam qualquer impacto sobre as importaçōes de trigo.

- em relação ao Mato Grosso do Sul, o impacto de medidas regionais e, exclusivamente para a soja, de reduçōes de custos e/ou subsídios à produção e ao transporte, destinadas a fazer competitiva a produção deste estado no mercado interno brasileiro.

\subsection{Taxas Alfandegárias Sobre a Soja Argentina.}

A simulação de imposições alfandegárias às importações de soja da Argentina visa determinar quais os niveis que tornam competitiva a produção brasileira de soja e quais as mudanças que estas taxas operam na soja nacional.

As taxas analisadas estão no intervalo da diferença entre os cus- 
tos de produção dos dois palses e foram fixadas como uma percentagem em relação ao custo de produção da soja no Brasil (US\$ 154,40/t). As mudanças, nas produçōes mencionadas abaixo, têm por base a situação da fase III da análise anterior.

Com taxas alfandegárias inferiores a 4\% (US\$ 6,18/t), não há nenhuma mudança em relação à situação da fase III.

Com uma taxa alfandegária de $6 \%$, fazendo com que o custo da soja argentina colocada no Brasil aumente US $\$ 9,26 / t$, haveria a substituição de 860 mil toneladas de soja importada por produção brasileira, para o abastecimento do Brasil. A expansão desta produção de soja se daria no Rio Grande do Sul.

Uma taxa alfandegária de 10\% (acréscimo de US\$ 15,44/t na soja argentina) resultaria em expansão desta cultura, também no Mato Grosso do Sul.

Taxas alfandegárias superiores a 15\% (US\$ 23,16/t) levariam à total auto-suficiência no abastecimento de soja no Brasil. A maior expansão da produção de soja ocorreria no Rio Grande do Sul (acréscimo de 2320 mil toneladas), seguido do Paraná (330 mil toneladas), Mato Grosso do Sul (320 mil toneladas) e nenhuma variação na produção de São Paulo.

A expansão da produção gaúcha se daria às custas de reduções na produção de milho e, no Paraná, pela substituição do arroz do sequeiro. Assim, a taxa de 15\% tornaria o Brasil auto-suficiente em soja. Mas ela faria com que o milho argentino fosse competitivo no mercado interno brasileiro, e a Argentina assumisse novamente seus compromissos de exportação de arroz, transferidos na fase III ao Brasil.

Em conclusão, as simulações mostram que, com os dois palses integrados como na fase III, uma taxa alfandegária de $15 \%$ na soja (ou equivalentemente uma redução no hiato dos custos de produção da soja de US $\$ 23,16 / t$ ) levaria o Brasil a substituir a importação de aproximadamente 2970 mil toneladas de soja da Argentina pela importação de 3150 mil toneladas de milho.

Verifica-se ainda que, isoladamente, a polftica de taxas alfandegárias sobre as importações de soja não tornaria a produção do Mato Grosso do Sul competitiva no mercado nacional. A sua produção de soja não ultrapassaria o nivel de sua demanda interna e o Brasil complementaria o seu abastecimento de milho com importações da Argentina e não com a expansão da produção para o Centro-Oeste. 


\subsection{Reduçōes nos Custos da Soja do Mato Grosso do Sul.}

A produção do Mato Grosso do Sul, pelos seus altos custos de produção e comercialização, não logra competitividade nos mercados dos demais estados. Porém, este estado apresenta disponibilidade de recursos e, portanto, capacidade para aumentar a sua produção. Sendo assim, para diminuir o impacto da integração sobre a economia desta região e/ou diminuir o nlvel das importações de soja argentina, sem afetar a auto-suficiência no abastecimento dos outros produtos considerados, precisar-se-ia aumentar a eficiência das atividades envolvidas com a produção de soja neste Estado ou a intervenção do governo em políticas deliberadas de apoio.

Nesta linha, as simulações feitas consideraram a redução de custos e/ou o abastecimento de subsídios à produção do Mato Grosso do Sul equivalentes a $15 \%$ dos custos de produção. Estes $15 \%$ (US\$ $27,45 /$ t) são próximos das diferenças entre os custos de produção do Estado (US\$183,00/t) e do Brasil (US\$154,40/t).

Sobre esta base, de redução de $15 \%$ nos custos de produção da soja do Mato Grosso do Sul, simularam-se situações caracterizadas pela inexistência de taxas alfandegárias sobre a importação da soja argentina e diminuições nos custos de comercialização variando entre 0 e $50 \%$.

Com a inexistência de taxas alfandegárias sobre a soja argentina, reduções de até $15 \%$ nos custos de produção e de até $30 \%$ nos custos de comercializaçāo da soja do Mato Grosso do Sul são incapazes de tornar a soja mato-grossense competitiva no mercado nacional, quando Brasil e Argentina estiverem integrados na situação da fase III. Ou seja, nestas condições, Mato Grosso do Sul continua produzindo soja para atender unicamente a sua demanda interna.

Com a inexistência de taxas alfandegárias e reduções de $15 \%$ nos custos de produção, níveis de $40 \%$ ou mais de redução nos custos de comercialização da soja do Mato Grosso do Sul resultariam em mudanças drásticas na estrutura de produção da soja brasileira. A produção gaúcha de soja seria reduzida a $15 \%$ do volume inicial, substituida pela do Mato Grosso do Sul. A produção do Paraná teria uma redução de apenas $3 \%$. Mas com a inexistência de taxas alfandegárias sobre a soja argentina, uma redução de $15 \%$ no custo de produção da soja do Mato Grosso do Sul, aliada a uma diminuição de $50 \%$ nos seus custos de comercialização, não alteraria o nível das importações de soja da Argen- 
tina. Estas continuariam no nivel de 2970 mil toneladas anuais.

Finalmente, simulou-se uma situação caracterizada pela imposição de uma taxa alfandegária de $10 \%$ (US $\$ 15,44 /$ t) sobre a soja argentina, uma redução de $15 \%$ (US $\$ 27,45 /$ t) no custo de produção e uma diminuição de $10 \%$ no custo de comercialização da soja no Mato Grosso do Sul.

Nesta situação, não haveria importações de soja da Argentina, sendo a produção brasileira competitiva para o abastecimento do mercado interno. Porém, os compromissos brasileiros para a exportação de soja em grãos, para terceiros países, continuariam sendo atendidos pela Argentina, significando que este pals seria mais competitivo no mercado mundial do que o Brasil.

\section{CONCLUSÕES}

Dentre os quatros produtos analisados, trigo, milho, soja e arroz, a Argentina apresenta vantagens absolutas de custos nos três primeiros e o Brasil, no último.

A maior diferença de custos de produção, entre os dois palses, existe em relação ao trigo. $O$ custo de produção da tonelada de trigo argentino corresponde a $30 \%$ do custo brasileiro.

A causa principal das vantagens absolutas no custo de produção da Argentina são as boas condiçōes de solo e clima. Devido à fertilidade natural do solo, a Argentina obtém altos rendimentos por unidade de área, com aplicações muito pequenas de fertilizantes. As condições favoráveis de clima, principalmente para o trigo, não propiciam infestaçōes de pragas, havendo pouco necessidade de uso de pesticidas.

O Brasil apresenta vantagens de custos na produção do arroz devido ao arroz irrigado do Rio Grande do Sul. Quanto aos quatros estados brasileiros analisados, o Rio Grande do Sul e Paraná apresentam custos de produção da tonelada de trigo inferiores aos de São Paulo e Mato Grosso do Sul. Estas diferenças são devidas aos custos variáveis, principalmente com sementes, fertilizantes, pesticidas e transportes até o primeiro local de compra-venda.

Em relação ao milho, São Paulo apresenta o menor custo de produção por tonelada e Mato Grosso do Sul, o maior dentre os estados brasileiros. Mas mesmo o custo de produção do milho de São Paulo é superior ao custo argentino. 
$\mathrm{Na}$ soja, o menor custo de produção dentre os estados brasileiros é o de São Paulo, sendo o do Mato Grosso do Sul o maior. Novamente, o custo da soja paulista é superior ao da soja argentina.

O custo de produção do arroz irrigado gaúcho é menor que o custo do arroz de sequeiro dos demais estados. Ele é inferior inclusive ao custo de produção do arroz irrigado argentino.

A integração Brasil-Argentina criaria fluxos de comércio da Argentina para o Brasil de trigo e, em menor dimensão, de soja. $O$ Brasil passaria a atender $75 \%$ de sua demanda por trigo com o produto argentino. A Argentina só não abasteceria totalmente o Brasil com trigo, devido aos seus compromissos de exportação com terceiros palses. Nà medida em que estes compromissos vencessem, o abastecimento do mercado brasileiro se faria integralmente com o produto argentino, desaparecendo a produção nacional, ao menos na sua forma comercial.

Como resultado da integração, a produção brasileira de soja seria reduzida em $34 \%$. A maior queda na produção de soja ocorreria no Mato Grosso do Sul, onde praticamente desapareceria. No Rio Grande do Sul, a queda seria de $16 \%$ e só de $3 \%$ no Paraná.

Não haveria fluxos de comércio de milho ou de arroz entre os dois países. Portanto, o milho argentino não é competitivo no mercado brasileiro, nem o arroz brasileiro o é no mercado argentino. Apenas no mercado mundial, o Brasil é mais competitivo do que a Argentina, em relação ao arroz, e este pals é mais competitivo em relação ao milho.

No Brasil, ocorreriam realocações estaduais na produção de milho e arroz. Haveria deslocamento da produção de milho do Mato Grosso do Sul para o Rio Grande do Sul, onde ocuparia áreas liberadas pela soja. Da mesma forma, diminuiria a produção de arroz no Mato Grosso do Sul, deslocada para o Paraná.

O impacto maior da integração recairia sobre o estado do Mato Grosso do Sul. Neste estado, haveria reduçōes drásticas na produção de trigo, soja, milho e, em menor dimensão, do arroz. Isto é devido aos seus maiores custos de produção e às distâncias que oneram o transporte dos produtos e insumos.

A integração não resultaria em grandes modificaçōes na produção dos grãos considerados no estado de São Paulo. Isto talvez seja devido à sua menor participação na produção de trigo e soja, que são as culturas menos competitivas frente aos produtos argentinos.

Nos estados do Rio Grande do Sul e do Paraná, os impactos da integração seriam de intensidade intermediária, quando comparados aos causados aos outros dois Estados. 
A simulação de taxas alfandegárias à importação da soja argentina mostrou que uma taxa de US\$ $23,16 /$ t (15\% do custo de produção brasileiro) estancaria as importaçōes de soja da Argentina. Porém o Brasil as substituiria por volumes praticamente iguais de importaçōes de milho. Da mesma forma, reduções nos custos de produção da soja do Mato Grosso do Sul de $15 \%$, aliadas a diminuições de $50 \%$ nos seus custos de comercialização, não alterariam o nivel de importação da soja da Argentina, quando os dois palses estivessem integrados. Haveria um deslocamento da produção gaúcha para o Mato Grosso do Sul, permanecendo o déficit nacional, a ser complementado pelas importações.

Finalmente com as ações combinadas, ou seja, aplicação de uma taxa alfandegária de $10 \%$ sobre a soja argentina e redução de $15 \%$ no custo de produção e de $10 \%$ no custo de comercialização da soja do Mato Grosso do Sul, a produção brasileira de soja seria competitiva no mercado interno, não havendo importaçōes deste produto. Igualmente, não haveria importaçōes de milho nem de arroz, da Argentina, permanecendo apenas as de trigo.

Estes resultados parecem indicar que, no caso da integração Brasil-Argentina, não é suficiente a redução do hiato de custos, entre os dois palses, de um produto que ocupa grandes áreas, se a mesma não vier acompanhada de medidas que possibilitem a integração da fronteira agrícola brasileira.

Sem a expansão da fronteira agrícola haveria substituição das importaçōes deste produto pelas de outro. A redução do hiato de custos pode ocorrer via desenvolvimento tecnológico, melhoras na infra-estrutura de.produção e comercialização, etc.

Da mesma forma, reduções de custos, numa região especlfica, de um produto que ocupe grandes áreas no país, não parecem ser suficientes para garantir o auto-abastecimento do pais.

Para tornar o país competitivo frente à Argentina, em relação ao produto agrícola que ocupe grandes áreas, parecem ser imprescindiveis dois tipos de medidas: reduções generalizadas de seu custo de produção e melhorias de infra-estrutura que possibilitem a incorporação das regiōes de fronteira no processo de produção.

\section{BIBLIOGRAFIA}

BASCO, C. Obstáculos al Comércio Intrarregional de Produtos Agropecuários. INTAL - Informa Preliminar, mimeografado. 1987. 
BASCO, C. El Costo de Transporte; una Barrera más al Comercio. In: Integración Latino-Americana. Buenos Aires, INTAL. 13(132): 3-15, Níarço, 1988.

BOLSA DE CEREALES DE BUENOS AIRES - Número Estadístico, 1986. Buenos Aires. 1987.

CIRIO, F. e REGUNAGA, M. La Producción de Granos Frente a los Condicionamientos del Mercado Mundial. In: Seminario: El Sector Agropecuario Ante la Crisis Agrícola Internacional. 19-21. Novembro, 1986. IICA. Buenos Aires, 1987.

FUENTES, H.A. Caracterizacion del Desarrollo Agrícola y del Minifundio en Argentina. Mimeografado, Bogotá, 1987. 55p.

FUNDAÇĀO INSTITUTO BRASILEIRO DE GEOGRAFIA E ESTATÍSTICA. Anuários Estatísticos do Brasil 1985 e 1986.

GUTIERREZ PEREZ, J. E. A Integração Brasil-Argentina: Um Estudo da Competitividade na Produção de Grãos. Porto Alegre, IEPE/ UFRGS, 1988. (Dissert. Mestrado em Econ. Rural, não publicada).

LEITE DA SILVA, G. Poítica Comercial Agrícola. In: Carta Mensal da SUPEC. CFP III(03):1-8, Braśllia, Março, 1988.

MARTIN, J. Desarrollo Regional Argentino: La Agricultura Cuadernos de la CEPAL, NN 38. CEPAL. Santiago. Chile. 1981.

ORTMANN, G.; STULP, V.; RASK, N. International Trade and Economic Development: Examples of Comparative Costs in Agricultural Commodities - Global Development Conference, University of Maryland, EEUU, Set. 1986.

PERKINS, P. R. Measuring Economic Competitiveness in Trade. USDA, ERS. Washington D. C. 1986.

ROSSETTI, J. P. Introdução à Economia. 9a Edição. São Paulo, Editora Atlas, 1982.

SALVATORE, D. Schaum's Outline of Theory and Problems of International Economics. 2a edição, Nova York, Mc Graw Hill Book Company, 1984.

SIMPÓSIO BRASILEIRO DE ALIMENTAÇÃO E NUTRIÇĀO (SIBAN). Subsídios ao Planejamento Agrícola em Função das Necessidades Nutricionais da População do Mato Grosso do Sul. Campo Grande, 14-19 de junho, 1987. 